GLUCOSE OXIDATION ON THE FIRST DAY OF LTFE IN VENTILATED VLBW INFANTS. 83 J.B. van Goudoever, E.J. Sulkers, Th. Efstathopoulos, Children's Hospital, Rotterdam, The Netherlands,

"Shriners Burns Inst., Boston / MIT Cambridge, Mass USA. Ventilated VLBw infants usually receive only glucose during the first day of life. These infants are prone to hypo- and hyper glycemia, and it is unknown if this is due to changes in glucose oxidation(Gluox) or non-oxidative disposal (NOD). We studied glucose turnover and oxidation in 7 ventilated VLBW infants birthweight $1.25 \pm 0.30 \mathrm{~kg}$; gestional age $32 \pm 2$ weeks; postnatal age $17 \pm 5 \mathrm{hrs}$ ) by a primed congtant infusion of the stable isotope age $17 \pm 5$ hro) by a primed contant infweion of the stable isotope from the plasma $(m+6)$ enrichment using GC-MS, glucose oxidation was measured $а{ }^{13}{ }^{13} \mathrm{CO}_{2}$ excretion in breath. Results as mean \pm 1 sd:

$\begin{array}{lcccc}\text { Results } & \text { gluc. int } & \text { Ra } & \text { Gluox } & \text { NOD } \\ \mathrm{mg} / \mathrm{kg} \cdot \mathrm{min} & 4.08 \pm 0.13 & 6.32 \pm 0.87 & 2.78 \pm 0.96 & 3.54 \pm 0.68\end{array}$

$4.08 \pm 0.13$

$.32 \pm 0.87 \quad 2.78 \pm 0.96 \quad 3.54 \pm 0.68$

Conclusion: 1. Endogenous glucose production was still present in all infants $(2.24 \pm 0.84 \mathrm{mg} / \mathrm{kg}$.d) 2 . Glucose oxidation was less than lucose disposal accounts for more than 50 of total Rate of appearance of glucose.

HYPOXIA PPRECEDES DEATH IN SIDS. POSSIBLE TRIGGER MECHANISMS.

84 Torleiv O Rognum, Lauritz Stoltenberg, Per S Thrane, Siri llauge, Ola D Saugstad - Inst of
Forens Med, Inst of pediatr Res, LIIPAT Inst of Pathol, University of Oslo, Norway lypoxanthine $(\mathrm{Hx})$ is formed from hypoxic degradation of AMP and is thus a marker of hypoxia. Results of Hx measurements in vitreous humor in 112 SIDS cases and in $2 l$ infants and children suffering sudden violent death, were corrected according to the expected postmortem $\mathrm{Hx}$ increase. The corrected median llx level of the SIDS group was 232 umol/1 (range $0-668$ umol/1), the sids group was 232 higher than the control group, which ls significantly higher than the control $g$. The fin $0 \mu \mathrm{mol} / 1$, (range $0-91 \mu \mathrm{mol} / 1),(\mathrm{p}<0.01)$. The finding of hypoxia in most cases.

Increased numbers of IgM-cells in the tracheal wall, IgA-cells in the duodenal mucosa and IgA-, IgM- and IgG-cells in the salivary gland in SIDS-victims, suggest an overstimulation of the mucosal inmune system in SIDS - perhaps caused by microbial factors. Such peripheral immune stimulation leads to release of cytokines which can induce immunostimulation in vital brain centres creating a vicious circle inducing hypbrain cel teath in infants at risk. Retrograde axonal transport might be a link to centres of the brain.

\section{BILIARY TRACT DYNAMICS DURING THE FIRST DAY OF LIFE}

\section{5}

Liisa Lehtonen. Erkki Svedström and Heikki Konenranta

Departments of Pediatrics and Radiology, Turku Univer sity, SF-20520 Turku, Finland

In order to evaluate the functional maturity of biliary tract at birth, repeated ultrasound scannings were carried out in 13 healihy newborn infants. All infants were nursed on breast from the age of 2 hours.

The gallbladder was full in all infants immediately after birth (longitudinal ellipsoid surface area $1.02 \mathrm{~cm}^{2}(0.44)$ (mean(sd)). No response was found to the first nursing. In 3 infants out of $9(33 \%)$ there was a full respose ( $100 \%$ emptying) during the first day of life while in $2(22 \%)$ the response was partial $(47-88 \%$ emptying from the initial volume). In the rest $4(44 \%)$ the gallbladder remained full during the first day of life. One of the infants showed no response during the first 3 days of life.

The biliary tract dynamics is highly variable after birth, possibly reflecting functional immaturity.

\section{EPIDEMIOLOGY}

RETROSPECTIVE AND PROSPECTIVE EPIDEMIOLOGY DATA OF INVASIVE HAEMOPHILUS INFL.UENZAE TYPE B (HIB)

86 INFECTIONS IN SWITZERLAND

Hanspeter E. Gnehm, Hanspeter Zimmermann - Children's Hospital, $\mathrm{CH}-5001$ Aarau and Federal Office of Public Health, $\mathrm{CH}-3001$ Berne, Switzerland

In Switzerland reporting of invasive $\mathrm{HiB}$ infections is mandatory for physicians (meningitis and septicemia) and laboratories (blood and CSF isolates) since Dec. 1987. We report on data of 529 prospectively collected cases from 1988 to 1990. Meningitis and prigtitis were the 2 most frequent types of infections representing $54 \%$ and $31 \%$ of all $\mathrm{HiB}$ diseases in the age group representing $54 \%$ and $31 \%$ of all $\mathrm{HiB}$ diseases in the age group 0-15 years respectively. The annul incidence (0-4 years) of meinfections. The peak incidence rates were observed between 6-12 months for meningitis and between 24-36 months for epiglottitis. Under the age of 6 months no epiglottitis was reported, whereas $5.6 \%$ of the meningitis patients were younger than 6 monlhs. $10 \%$ of all $\mathrm{HiB}$ infections occurred in children betiveen 5 and 15 years. The case fatality rate was higher for meningitis (2.5\%) years. The case fatality rate was higher for meningitis than for epiglottitis (1.2\%). The retrospective studies in the fataliiy rates and very similar age distributions for the above mentioned infections. The results warrant an immunization progranme, which will be surveyed by the actual reliable reporting system.

Coronary Risk Factors in Schoolchildren: Preliminary Findings of the Northern Ireland Young Hearts Project 87 Primrose EO, Savage JM, Boreham CAG, Cran GW. Statistics, The Queen's University of Belfast.

Northern Ireland (NI) lies at the top of the world mortality league for Adult Coronary Heart Disease (CHD). We have evaluated coronary risk factor status in a random stratified sample of 1015 school children, comprising 251 12-year-old boys, 258 12-year-old girls, 252 15-year-old boys and 254 15-year old girls. The protocol included a physical examination, fitness testing and dietary analysis. Blood samples were obtained from 1012 children for serum total cholesterol determination. The overall response rate was $76 \%$ with a determination. The overall response rate was $76 \%$ with a parental questionnaire return rate of $93 \%$ in responders. The
prevalence of obesity was $9.6 \%, 10.4 \%, 12.3 \%$ and $29.5 \%$ in boys and girls, aged 12 years and 15 years respectively. THe corresponding cholesterol levels were $4.6 \mathrm{mmol} / 1,4.7 \mathrm{mmol} / 1$, $4.2 \mathrm{mmol} / 1$ and $4.6 \mathrm{mnol} / 1$. No significant relationship was identified between total cholesterol and family history of premature coronary heart disease. These results indicate a high prevalence of obesity particularly in 15-year-old girls and unfavourable cholesterol levels in all 4 age-sex groups.
PASSIVE SMOKING AND URINE COTININE LEVELS IN GRETK CHILDREN

88 Chryssa Bakoula, Despina Lazopoulou, Mary

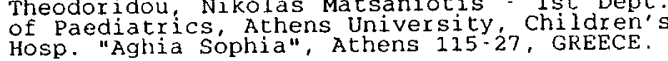

The high prevalence of cigarette smoking in Greece made worth an attempt to documenting passive smoking anong children. A precoded questionnaire was completed by three paediatricians for 565 randomly select In all 565 children urine cotinine levels were measured by radioimmunoassay and standardised by the cotinine creatinine ratio. It was found that: 1 . Most Greek children ( 808 ) are passive smokers as in watio (53.4 列 the source of indoor popution by cigarette smoke, a lone $(11 \%)$ or along with father $(33 \%)$. 3. From variant and regression analysis a statistically significant association was identified between urine cotinine levels in children and the following main factors by descending order of p values: number of smokers at home (positive), child's age (negative) number of (negative), maternal education (negative).

In conclusion antismoking compaing has to be reinforced rn conclusion antismoking compaing has to be reinforced participate. 